\title{
Thermolysis Kinetics of 1,1-Bis(t-butyldioxy)cycloalkanes and Their Utility for Styrene Polymerization
}

\author{
Shuji SuYama, ${ }^{*}$ Hideyo IshigaKi, Tomoyuki NaKamura, \\ Yasushi SugIhara, Hiromi Kumura, \\ and Yasumasa WATANABE
}

Fine Chemicals \& Polymers Research Laboratory, NOF Corporation, Taketoyo-cho, Chita-gun, Aichi 470-23, Japan

(Received July 26, 1993)

\begin{abstract}
Thermolysis kinetics of 1,1-bis( $t$-butyldioxy)cycloalkanes (cycloalkane perketals) with various alkyl substituents on the cycloalkane rings were investigated in cumene. Substitution at the 2-position on the ring greatly accelerated the peroxide decomposition; the accelerating effect of substituents is in the order $\mathrm{H}<n-\operatorname{Pr} \approx \mathrm{Me}<$ iso-Pr. The bulk polymerization of styrene initiated by cycloalkane perketals proceeded via the two-step $\mathrm{O}-\mathrm{O}$ decomposition and gave higher molecular weight polymers than polymerization by monofunctional initiators. It is shown that cycloalkane perketals act as unsymmetrical difunctional initiators.
\end{abstract}

KEY WORDS Styrene / Radical Polymerization / Cycloalkane Perketal /

Difunctional Initiator / Kinetics /

Organic peroxides are used widely as polymerization initiators in the polymer industry and numerous organic peroxides have been developed so far. ${ }^{1}$ For polymer makers, it is important to produce polymers having the desired molecular weight at high polymerization rate to reduce production cost. Organic peroxide initiators play an important role in controlling molecular weight and polymerization rate. Although thermally active initiators which decompose at relatively low temperature can increase polymerization rate effectively, the high polymerization rate causes lowering of molecular weight of the resulting polymer. This is because polymer molecular weight is inversely proportional to polymerization rate in conventional free radical polymerization.

Recently, it was reported that difunctional peroxides which possess two $\mathrm{O}-\mathrm{O}$ bonds in a molecule are more effective initiators for the production of desired polymers at high polymerization rate than conventional monofunctional peroxides. ${ }^{2-8}$ Among difunctional peroxides, particular attention has been paid to decomposition and initiation chemistries of gem-diperoxides (perketals). ${ }^{9-16}$ We reported several studies on the thermal decomposition of acyclic (1) ${ }^{9}$ and cyclic perketals (2a) ${ }^{10}$ and initiation mechanism for the polymerization of vinyl monomers with perketals. ${ }^{1-13}$

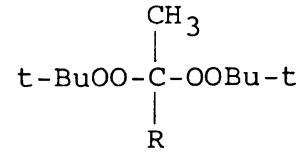

(1)

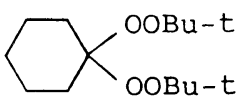

(2a)
For example, we showed that the initial decomposition of 2 a occurs by mainly one $\mathrm{O}-\mathrm{O}$ bond fission, the resulting cycloalkoxy radical undergoes ring opening before addition to

\footnotetext{
* To whom all correspondence should be addressed.
} 
styrene monomer (eq 1a), and then the initiates the polymerization of styrene effecring-opened radical (3) having a perester group tively (eq 2). ${ }^{13}$

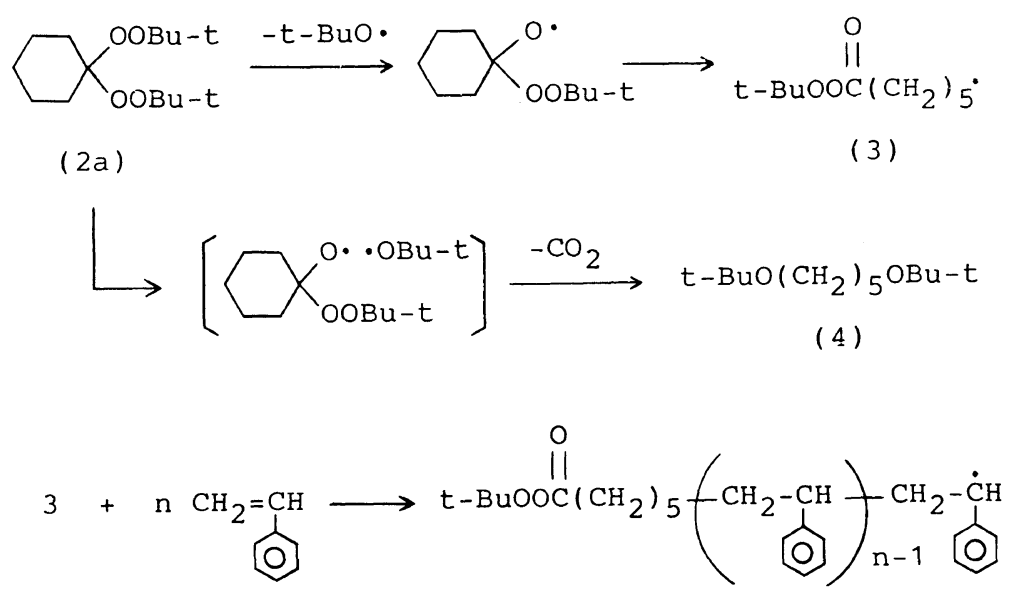

Since the $\mathrm{O}-\mathrm{O}$ bond of the perester group is also thermally unstable, the resulting polymer having the perester group will further initiate polymerization. Thus, it is expected that cycloalkane perketals act as unsymmetrical difunctional initiators which have two $\mathrm{O}-\mathrm{O}$ bonds differing in thermal stability (i.e., dialkyl and perester types). As another competitive path in $2 \mathrm{a}$ decomposition, more recently, Drumright et al. ${ }^{14,15}$ reported that an in-cage decomposition (eq 1b) occurs resulting in the formation of diether (4). However, since the yield of 4 is not so high ( $<10 \%$ for decomposition in ethylbenzene), the major decomposition path can be expressed as eq $1 \mathrm{a}$ and 2 .

It is well known that peroxide decomposition is affected by certain substituents due to steric and inductive effects. Therefore, it can be expected that the decomposition temperature (i.e., thermal activity) of the two $\mathrm{O}-\mathrm{O}$ bonds of cycloalkane perketals can be suitably altered by the introduction of substituents on the cycloalkane ring.

This paper reports the thermolysis kinetics of cycloalkane perketals (2) having various alkyl substituents on the cycloalkane rings, and their utility for polymerization of styrene as initiators.

\section{RESULTS AND DISCUSSION}

\section{Thermolysis of Cycloalkane Perketals}

Seven cycoalkane perketals $(2 \mathrm{a}-2 \mathrm{~g})$ having five or six-membered ring were prepared by the reaction of $70 \% t$-butyl hydroperoxide with the corresponding cyclic ketones in the presence of $65 \%$ sulfuric acid (eq 3 ). Their structures were ascertained by ${ }^{1} \mathrm{H}$ NMR, ${ }^{13} \mathrm{C}$ NMR, and other spectral measurements. Purity was determined by iodometric titration and GLC analysis and found to be over $98 \%$ for each peroxide.
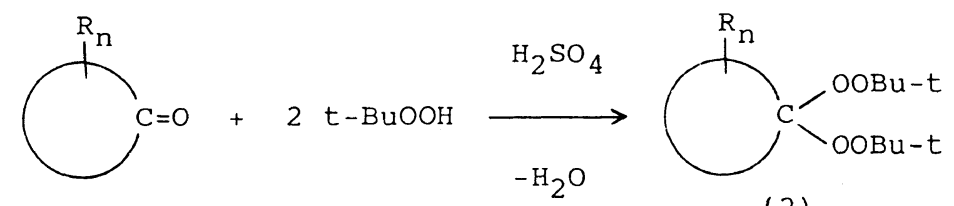


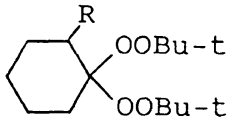

$(2 \mathrm{a}): \mathrm{R}=\mathrm{H}$

$(2 \mathrm{~b}): \mathrm{R}=\mathrm{Me}$

$(2 c): R=n-P r$

(2d): $R=i-P r$

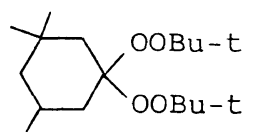

(2e)

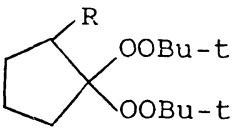

$(2 \mathrm{f}): \mathrm{R}=\mathrm{H}$

$(2 g): R=M e$

Table I. Rate constants and activation parameters for the decomposition of cycloalkane perketals 2 in cumene

\begin{tabular}{|c|c|c|c|c|c|}
\hline \multirow{3}{*}{ Perketal $^{a}$} & \multirow{3}{*}{$\frac{\text { Temp }}{{ }^{\circ} \mathrm{C}}$} & \multirow{3}{*}{$\frac{k \times 10^{5}}{\mathrm{~s}^{-1}}$} & \multirow{3}{*}{$\begin{array}{c}k_{\text {rel }} \\
\left(100^{\circ} \mathrm{C}\right)\end{array}$} & \multicolumn{2}{|c|}{ Activation parameters } \\
\hline & & & & \multirow{2}{*}{$\frac{\Delta H^{\ddagger}}{\mathrm{kJ} \mathrm{mol}^{-1}}$} & \multirow{2}{*}{$\frac{\Delta S^{\neq}}{\mathrm{J} \mathrm{K}^{-1} \mathrm{~mol}^{-1}}$} \\
\hline & & & & & \\
\hline \multirow[t]{4}{*}{$2 \mathrm{a}$} & 80 & 0.347 & & & \\
\hline & 90 & 1.45 & & & \\
\hline & 100 & 5.06 & $(1.0)$ & 139.5 & 44.8 \\
\hline & 110 & 16.2 & & & \\
\hline \multirow[t]{4}{*}{$2 b$} & 80 & 1.29 & & & \\
\hline & 90 & 4.51 & & & \\
\hline & 100 & 14.3 & 2.8 & 130.4 & 29.6 \\
\hline & 110 & 45.8 & & & \\
\hline \multirow[t]{3}{*}{$2 \mathrm{c}$} & 80 & 1.20 & & & \\
\hline & 90 & 4.19 & & & \\
\hline & 100 & 13.8 & 2.7 & 130.6 & 29.4 \\
\hline \multirow[t]{4}{*}{$2 d$} & 70 & 2.59 & & & \\
\hline & 80 & 4.86 & & & \\
\hline & 90 & 19.8 & & & \\
\hline & 100 & 74.6 & 14.7 & 118.6 & 9.9 \\
\hline \multirow[t]{4}{*}{$2 e$} & 80 & 0.382 & & & \\
\hline & 90 & 1.50 & & & \\
\hline & 100 & 5.31 & 1.0 & 140.0 & 47.2 \\
\hline & 110 & 17.5 & & & \\
\hline \multirow[t]{4}{*}{$2 \mathrm{f}$} & 80 & 0.498 & & & \\
\hline & 90 & 1.80 & & & \\
\hline & 100 & 6.67 & 1.3 & 139.0 & 45.6 \\
\hline & 110 & 21.7 & & & \\
\hline \multirow[t]{4}{*}{$2 \mathrm{~g}$} & 80 & 1.55 & & & \\
\hline & 90 & 5.82 & & & \\
\hline & 100 & 18.5 & 3.7 & 133.3 & 39.3 \\
\hline & 110 & 60.0 & & & \\
\hline
\end{tabular}

a Initial concentration, $0.05 \mathrm{moll}^{-1}$.

The thermal decomposition of 2 was carried first-order kinetics over two half-lives reaction. out in cumene under nitrogen. The thermolysis The resulting rate constants and activation rates, as determined by measuring the dis- parameters are listed in Table I. In the case of appearance of 2 by GLC analysis, satisfied $2 \mathrm{a}$, the rate constants were not influenced by 
change in initial concentration $(0.02-0.2 \mathrm{M})$. This indicates that attack of radicals on perketals (induced decomposition) hardly occurs under the present conditions.

It is clear from Table I that substitution at the 2-position on the cycloalkane ring accelerates peroxide decomposition significantly, while substitution at the 3-position little affects peroxide decomposition. For example, the accelerating effect of 2-alkyl substituents increased in the order $\mathrm{H}<n-\mathrm{Pr} \approx \mathrm{Me}<$ iso- $\mathrm{Pr}$ $(1: 2.7 \approx 2.8: 14.7)$. It is notable that the accelerating effect of the iso-Pr group is about five times that of the $n$-Pr group. This clearly demonstrates that steric effects are important factors controlling the decomposition of cycloalkane perketals.

The activation parameters $\left(\Delta H^{\ddagger}\right.$ and $\left.\Delta S^{\ddagger}\right)$ for iso-Pr substituted perketal (2d) are quite small. In 1958, Bartlett and Hiatt ${ }^{16}$ represented the relationship between $\Delta H^{\ddagger}$ and $\Delta S^{\ddagger}$ for a large number of t-butyl peresters and demonstrated that peresters undergoing concerted decomposition give relatively small $\Delta H^{\ddagger}$ and $\Delta S^{\ddagger}$. Since perketals decompose homolytically like peresters, it is reasonable to expect that a similar relationship between $\Delta H^{\ddagger}$ and $\Delta S^{\ddagger}$ exists for perketals. That is, small $\Delta H^{\ddagger}$ and $\Delta S^{\ddagger}$ for $2 \mathrm{~d}$ indicate that the decomposition of $2 \mathrm{~d}$ occurs by mainly two-bond homolysis mechanism (eq 4). The mechanism is supported by the following. i) The iso-Pr.substituent can stabilize the ring-opened alkyl radical. ii) The bulky iso-Pr group increases the ring strain of the reactant perketal, but the strain can be cancelled out by decomposition.

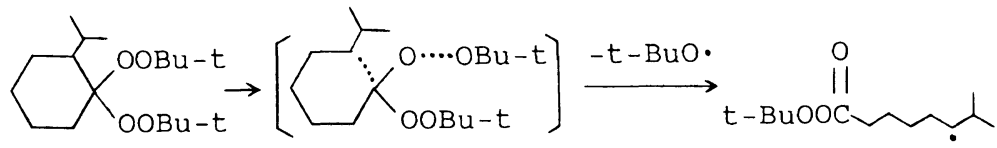

(2d)

The effect of ring size, five and six-members, was not so large. For example, the cyclopentane perketals decompose only 1.3 times faster than the corresponding cyclohexane perketals. Matsuyama and Kumura ${ }^{17}$ reported a more detailed study on the effects of ring size on the decomposition of cycloalkane perketals. They showed that the rates of decomposition decrease with increasing ring size. The relative decomposition rates of cyclopentane/cyclohexane/cyclooctane/ cyclododecane perketals are $1.3 / 1.0 / 0.8 / 0.6$ at $110^{\circ} \mathrm{C}$. These results indicate that ring size does not markedly influence the decomposition of cycloalkane perketals.

\section{Thermolysis of Polymer Peroxide}

We previously showed that the polymerization of styrene with 2 a mainly proceeds through the formation of polymer peroxide (PPO) with the perester group (eq la and 2). ${ }^{13}$ Though the precise decomposition rate of PPO is unclear, we can roughly estimate it from the known structure-activity relationship of peresters. It is well known that the decomposition rates of peresters mainly depend on the structures of carboxylic acid moieties of peresters. ${ }^{16,18}$ With peresters derived from aliphatic carboxylic acids, their decomposition rates significantly depend on the degree of $\alpha$-branch of the carboxylic acid moiety as shown below ${ }^{18}$ :

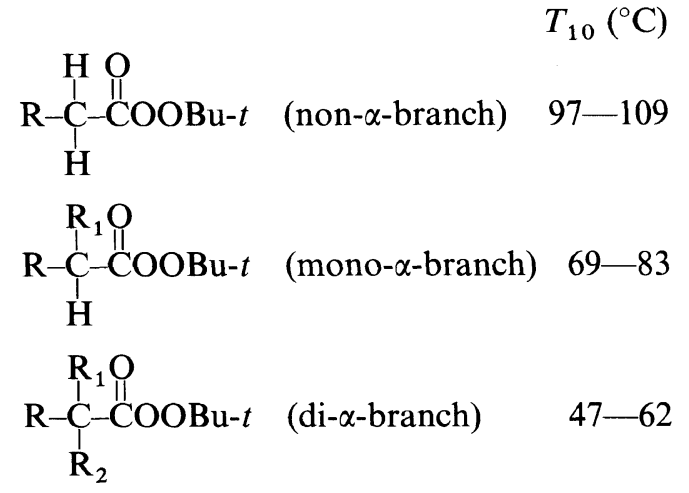


Where $T_{10}$ means the temperature at which the peroxide is $50 \%$ decomposed in 10 hours. Since PPO formed by 2 a contains the perester group derived from non- $\alpha$-branched carboxylic acid, the decomposition rate is assumed to be equal to those of lower linear peresters, e.g., $t$-butyl peroxylaurate (TBPL).
The $\mathrm{O}-\mathrm{O}$ homolysis of $2 \mathrm{~b}-2 \mathrm{~d}$ will also give intermediate cycloalkoxy radicals with 2-alkyl substituents on the cyclohexane ring. The alkoxyl radicals may undergo two possible ring openings to afford primary alkyl radicals (eq $5 a)$ or secondary alkyl radicals (eq 5b).
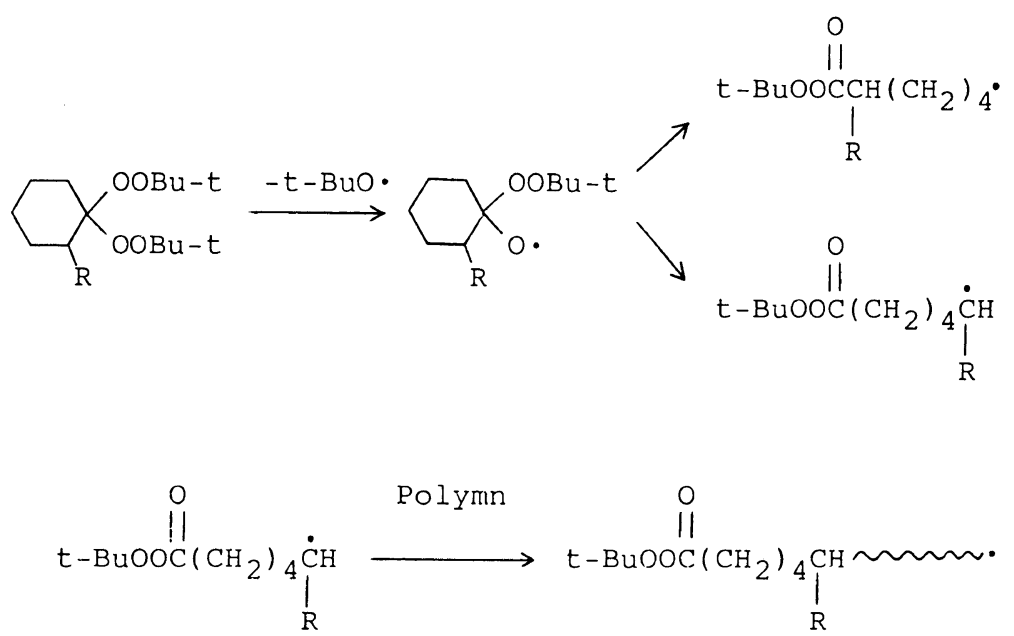

It is well known that the $\beta$-scission of alkoxy radicals takes place predominantly to produce more stable radicals. ${ }^{19-21}$ For example, the rate of elimination of secondary alkyl radicals is approximately 50 times faster than the elimination of primary alkyl radicals. ${ }^{21}$ Therefore, it is reasonable to assume that eq 5 b occurs mainly and the more stable secondary alkyl radicals initiate the polymerization of styrene. Thus, it is predictable that the polymerization of styrene initiated by $2 \mathrm{~b}-2 \mathrm{~d}$ also proceeds through the formation of PPO with the perester group derived from the non- $\alpha$-branched carboxylic acid.

\section{Polymerization of Styrene}

First, we carried out the two-stage bulk polymerization of styrene using iso-Pr-substituted perketal $2 \mathrm{~d}$ as the initiator. The polymerization temperature was increased stepwise from 80 to $110^{\circ} \mathrm{C}$. For comparison, the same polymerizations were carried out using mono functional peroxides as initiators. Here, we used $t$-butyl peroxy-2-ethylhexanoate (TBPE) and TBPL as monofunctional initiators, since $T_{10}$ of TBPE and TBPL are expected to be comparable to the lower and higher $T_{10}$ of $2 \mathrm{~d}$, respectively (Table II). As seen from the time-conversion curves (Figure 1 ), in the first stage polymerization at $80^{\circ} \mathrm{C}$, the slope for $2 \mathrm{~d}$ was similar to that for TBPE (higher active monofunctional initiator). In the second stage polymerization at $110^{\circ} \mathrm{C}$, the slope for $2 \mathrm{~d}$ was similar to that for TBPL (lower active monofunctional initiator). This clearly demonstrates that the thermal stability of the peroxide groups of $2 \mathrm{~d}$ is not the same and suggests that the polymerization activity of $2 d$ is nearly equal to that of the mixture of TBPE and TBPL.

Next, we carried out non-isothermal bulk polymerizations of styrene with $2 \mathrm{~d}$ and the mixture of TBPE and TBPL. The polymerization temperature was continuously increased 
Table II. Two-stage bulk styrene polymerization ${ }^{\mathrm{a}}$

\begin{tabular}{|c|c|c|c|}
\hline \multirow{2}{*}{ Initiator $^{\mathbf{b}}$} & \multirow{2}{*}{$T_{10} /{ }^{\circ} \mathrm{C}$} & \multicolumn{2}{|c|}{ Conversion $/ \%$} \\
\hline & & $1 \mathrm{st}^{\mathrm{c}}$ & $2 \mathrm{nd}^{\mathrm{d}}$ \\
\hline \multicolumn{4}{|c|}{ (A) Polymerization with perketal } \\
\hline & $\begin{array}{r}69.6^{\mathrm{e}} \\
100.1^{\mathrm{f}}\end{array}$ & 39.6 & 97.6 \\
\hline \multicolumn{4}{|c|}{ (B) Polymerization with monofunctional peroxide } \\
\hline TBPE & 75.5 & 31.7 & 74.2 \\
\hline TBPL & 100.1 & 7.6 & 90.6 \\
\hline \multicolumn{4}{|c|}{$\begin{array}{l}\text { a Polymerization temperature was increased stepwise } \\
\text { from } 80 \text { to } 110^{\circ} \mathrm{C} \text {. } \\
\text { b Initial concentration, } 5 \mathrm{mM} \text {. TBPE, } t \text {-butyl peroxy-2- } \\
\text { ethyl hexanoate; TBPL, } t \text {-butyl peroxylaurate. } \\
\text { c After the first stage polymerization at } 80^{\circ} \mathrm{C} \text { for } 5 \mathrm{~h} \text {. } \\
\text { d After the second stage polymerization at } 110^{\circ} \mathrm{C} \text { for } 5 \mathrm{~h} \text {. } \\
\text { e } T_{10} \text { for the first decomposing } \mathrm{O}-\mathrm{O} \text { bond. } \\
\text { f } T_{10} \text { for the second decomposing } \mathrm{O}-\mathrm{O} \text { bond. }\end{array}$} \\
\hline
\end{tabular}

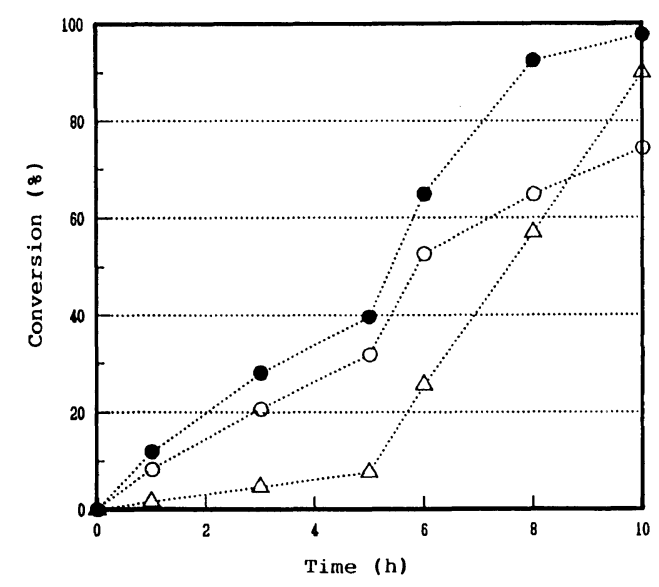

Figure 1. Time-conversion relationships for two-stage bulk styrene polymerization at $80^{\circ} \mathrm{C}(0-5 \mathrm{~h})$ and $110^{\circ} \mathrm{C}$ (5-10h): [initiator], $5 \mathrm{mM}$; (О) 2d; (O) TBPE; $(\triangle)$ TBPL.

from 80 to $140^{\circ} \mathrm{C}$. The resulting time-conversion curves are shown in Figure 2. As expected, the curves for $2 \mathrm{~d}$ were in good agreement with those for the mixed initiator when the same initiator concentration was used. GPC curves for $2 \mathrm{~d}$ were uimodal but somewhat broader than those for the mixed initiator. The effect of $2 \mathrm{~d}$ on the polymer molecular weight properties is shown in Table III and Figure 3.

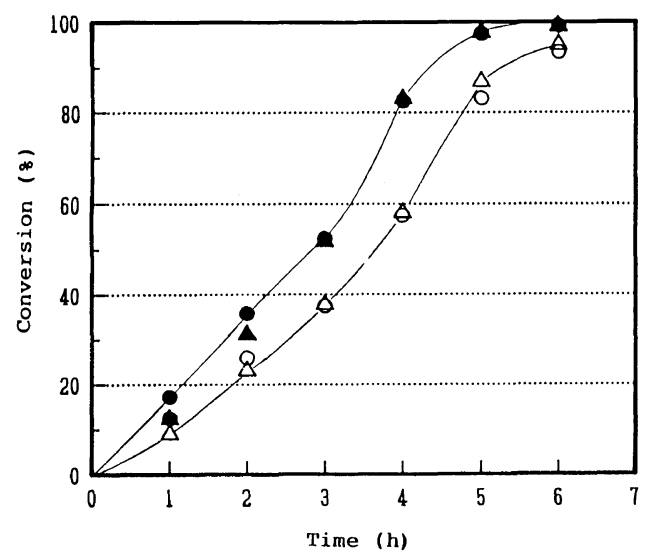

Figure 2. Time-conversion relationships for bulk styrene polymerization at continuously increasing temperature from 80 to $140^{\circ} \mathrm{C}\left(10^{\circ} \mathrm{Ch}^{-1}\right)$ : (O) $2 \mathrm{~d}(2.5 \mathrm{mM})$; (O) $2 \mathrm{~d}$ $(5 \mathrm{mM}) ;(\triangle)$ TBPE $(2.5 \mathrm{mM})+\operatorname{TBPL}(2.5 \mathrm{mM}) ;(\boldsymbol{\Delta}) \mathrm{TBPE}$ $(5 \mathrm{mM})+$ TBPL $(5 \mathrm{mM})$.

Table III. Comparison of perketal initiator $2 \mathrm{~d}$ and mixed mono-functional initiators in bulk styrene polymerization ${ }^{a}$

\begin{tabular}{|c|c|c|c|c|}
\hline \multirow{2}{*}{ Initiator } & Concn & Conversion $^{\mathrm{b}}$ & \multirow{2}{*}{$10^{-4} \bar{M}_{w}^{\mathrm{b}}$} & \multirow{2}{*}{$\bar{M}_{w} / \bar{M}_{n}^{\mathrm{b}}$} \\
\hline & $\mathrm{mM}$ & $\%$ & & \\
\hline \multirow[t]{2}{*}{$2 d$} & 2.5 & 93.5 & 41.8 & 1.97 \\
\hline & 5.0 & 99.3 & 35.0 & 2.25 \\
\hline \multirow[t]{2}{*}{$\operatorname{Mix}^{\mathrm{c}}$} & $2.5^{\mathrm{d}}$ & 95.1 & 33.2 & 1.84 \\
\hline & $5.0^{\mathrm{d}}$ & 99.0 & 27.8 & 2.02 \\
\hline
\end{tabular}

a Polymerization temperature was increased continuously $\left(10^{\circ} \mathrm{C} \mathrm{h}^{-1}\right)$ from 80 to $140^{\circ} \mathrm{C}$.

b After polymerization for $6 \mathrm{~h}$.

c Mixture of TBPE and TBPL.

d Concentration of each monofunctional initiator.

Compared with the use of mixed monofunctional initiators, it is clear that when $2 \mathrm{~d}$ is used, the polymer molecular weight considerably increases with increase in monomer conversion, and higher molecular weight polymers with slightly larger polydispersity $\left(\bar{M}_{w} / \bar{M}_{n}\right)$ can be obtained finally. These results are easily understood due to the formation of intermediate polymer peroxide having the ability to further initiate polymerization. Thus, it was confirmed that $2 \mathrm{~d}$ acts as a typical unsymmetrical difunctional initiator. 


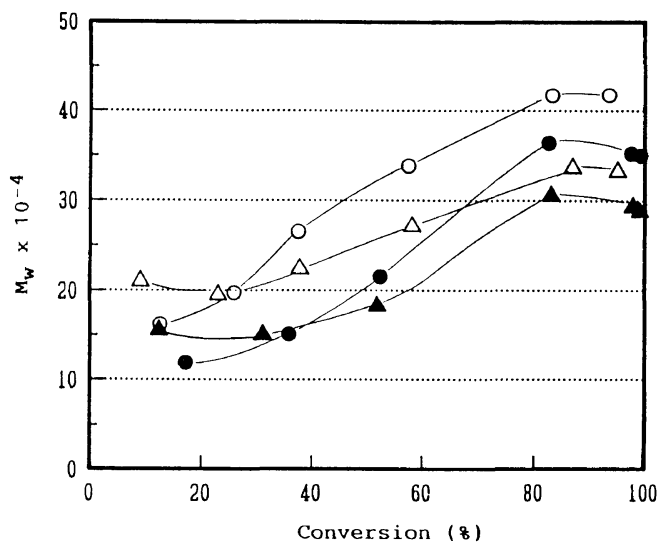

Figure 3. Effect of perketal initiator $2 d$ on polymer molecular weights in bulk styrene polymerization at continuously increasing temperature from 80 to $140^{\circ} \mathrm{C}$ $\left(10^{\circ} \mathrm{Ch}^{-1}\right)$ : (О) $2 \mathrm{~d}(2.5 \mathrm{mM}) ;(\bigcirc) 2 \mathrm{~d}(5 \mathrm{mM}) ;(\triangle) \mathrm{TBPE}$ $(2.5 \mathrm{mM})+$ TBPL $(2.5 \mathrm{mM}) ;(\boldsymbol{\Delta})$ TBPE $(5 \mathrm{mM})+$ TBPL $(5 \mathrm{mM})$.

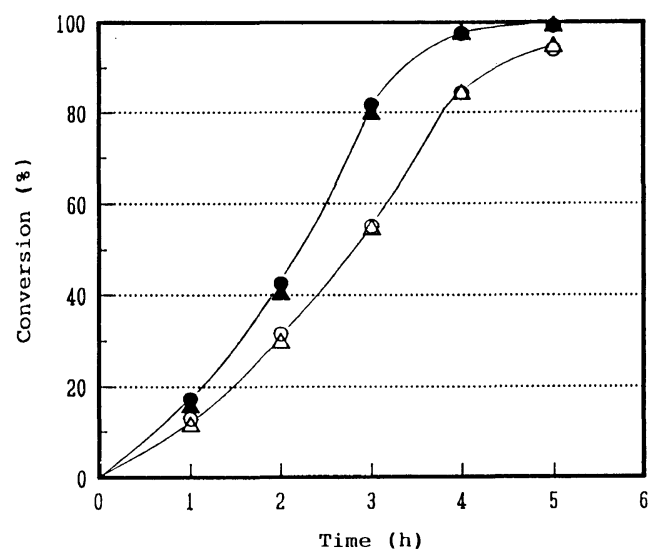

Figure 4. Time-conversion relationships for bulk styrene polymerization at continuously increasing temperature from 90 to $140^{\circ} \mathrm{C}\left(10^{\circ} \mathrm{Ch}^{-1}\right)$ : (○) $2 \mathrm{~b}(2.5 \mathrm{mM}) ;(\bigcirc) 2 \mathrm{~b}$ $(5 \mathrm{mM}) ;(\triangle)$; THMC $(2.5 \mathrm{mM})+$ TBPL $(2.5 \mathrm{mM}) ;(\boldsymbol{\Delta})$ THMC (5 mM) + TBPL (5 mM).

Similarly, bulk styrene polymerization initiated by Me-substituted perketal $2 \mathrm{~b}$ was carried out under the non-isothermal conditions. For comparison, the same polymerization was carried out using a binary mixture of monofunctional initiators consisting of 1-thexyldioxy-1-methoxy cyclohexane (THMC) and TBPL. As seen in Figure 4, the time-
Table IV. Comparison of perketal initiator $2 b$ and mixed mono-functional initiators in bulk styrene polymerization ${ }^{a}$

\begin{tabular}{|c|c|c|c|c|}
\hline \multirow[t]{2}{*}{ Initiator $^{b}$} & \multirow{2}{*}{$T_{10} /{ }^{\circ} \mathrm{C}$} & Conversion $^{\mathrm{c}}$ & \multirow{2}{*}{$10^{4} \bar{M}_{w}{ }^{\mathrm{c}}$} & \multirow{2}{*}{$\bar{M}_{w} / \bar{M}_{n}^{\mathrm{c}}$} \\
\hline & & $\%$ & & \\
\hline $2 b$ & $\begin{array}{r}85.2^{\mathrm{d}} \\
100.1^{\mathrm{e}}\end{array}$ & 99.2 & 32.4 & 2.06 \\
\hline THMC $^{\mathrm{f}}$ & 86.2 & & & \\
\hline $\begin{array}{r}+ \\
\text { TBPL }\end{array}$ & 100.1 & 99.1 & 26.4 & 1.89 \\
\hline
\end{tabular}

a Polymerization temperature was increased continuously $\left(10^{\circ} \mathrm{C} \mathrm{h}^{-1}\right)$ from 90 to $140^{\circ} \mathrm{C}$.

b Initial concentration: $2 \mathrm{~b}, 5 \mathrm{mM}$; THMC, $5 \mathrm{mM}$; TBPL, $5 \mathrm{mM}$.

c After polymerization for $5 \mathrm{~h}$.

d $T_{10}$ for the first decomposing $\mathrm{O}-\mathrm{O}$ bond.

e $T_{10}$ for the second decomposing $\mathrm{O}-\mathrm{O}$ bond.

f 1-t-Hexyldioxy-1-methoxycyclohexane.

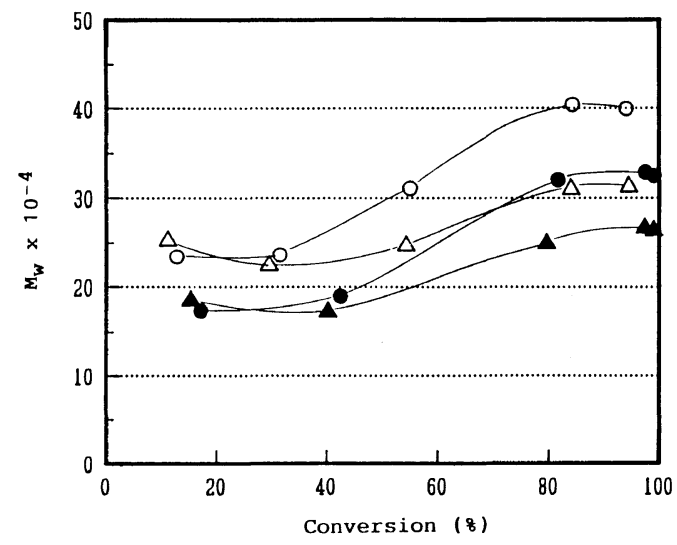

Figure 5. Effects of perketal initiator $2 b$ on polymer molecular weights in bulk styrene polymerization at continuously increasing temperature from 90 to $140^{\circ} \mathrm{C}$ $\left(10^{\circ} \mathrm{Ch}^{-1}\right)$ : (O) $2 \mathrm{~b}(2.5 \mathrm{mM}) ;(\bigcirc) 2 \mathrm{~b}(5 \mathrm{mM}) ;(\triangle)$ THMC $(2.5 \mathrm{mM})+$ TBPL $(2.5 \mathrm{mM})$; (A) THMC (5 mM) + TBPL (5 mM).

conversion curves for $2 b$ are in good agreement with those for the mixed initiator. This indicates that $2 \mathrm{~b}$ also has two thermally different $\mathrm{O}-\mathrm{O}$ bonds and our estimation of the thermal stability of each $\mathrm{O}-\mathrm{O}$ bond was accurate. As seen from Table IV and Figure 5, perketal initiator $2 b$ showed the same effect as $2 \mathrm{~d}$ on the polymer molecular weight properties. 
In conclusion, the polymerization of styrene initiated by cycloalkane perketals proceeds via the formation of polymer peroxide with the perester group which can further initiate styrene polymerization. That is, cycloalkane perketals act as typical unsymmetrical difunctional initiators with two thermally different $\mathrm{O}-\mathrm{O}$ bonds. The introduction of a bulky group (e.g., iso-Pr group) at the 2-position on the cycloalkyl ring greatly accelerates the $\mathrm{O}-\mathrm{O}$ decomposition due to mainly steric effect. Such perketals with the large difference in decomposition temperature between the two $\mathrm{O}-\mathrm{O}$ bonds should be useful as initiators for block polymer syntheses.

\section{EXPERIMENTAL}

\section{Measurements}

IR and NMR spectra were recorded on a JASCO A-3 and a JEOL JNM-GSX 270 spectrometers, respectively. GLC analyses were performed with a Shimadzu GC-14A gas chromatograph with a flame ionization detector using a $15 \mathrm{~m}$ flexible fused silica capillary column $(0.53 \mathrm{~mm}$ in diameter $)$ coated with silicone OV-1. A Shimadzu Chromatopac C-R4A integrator was used for quantitative analyses. Mass spectra were obtained on a JEOL JMS- DX300 mass spectrometer at $70 \mathrm{eV}$ under electron impact conditions. GPC analysis was conducted on a Shimadzu LC-6A equipped with a Shimadzu RID-6A using THF as the eluent. Two columns, a Shodex KF-80M $(60 \mathrm{~cm})$ and Shimadzu HSG-10S $(60 \mathrm{~cm})$, were connected in series. The calibration curve was made using standard samples of polystyrene.

\section{Materials}

1,1-Bis(t-butyldioxy)cyclohexane (2a) was prepared by methods previously described. ${ }^{10}$ Other cycloalkane perketals were prepared using the corresponding cyclic ketones.

Monofunctional peroxides, $t$-butyl peroxylaurate (TBPL) and $t$-butyl peroxy-2-ethylhexanoate (TBPE), were commercially available.
1- $t$-Hexyldioxy-1-methoxycyclohexane (THMC) was prepared by the following procedure: To dimethyl sulfoxide $(16.0 \mathrm{~g})$ containing $p$-toluenesulfonic acid $(1.3 \mathrm{~g})$ was added dropwise a mixture of 1,1-dimethoxycyclohexane $(28.8 \mathrm{~g})$ and $t$-hexyl hydroperoxide $(23.8 \mathrm{~g})$ at $20^{\circ} \mathrm{C}$. After being stirred for $3 \mathrm{~h}$ at $20^{\circ} \mathrm{C}$, the reaction mixture was diluted by the addition of petroleum ether $20 \mathrm{ml}$, washed with $5 \%$ aqueous $\mathrm{NaOH}$ and water, dried over anhydrous sodium sulfate, and then evaporated to dryness. Vacuum distillation of the crude product yielded THMC as a colorless oil with bp 47$50^{\circ} \mathrm{C} / 0.1 \mathrm{mmHg} .{ }^{1} \mathrm{H}$ NMR $\left(\mathrm{CDCl}_{3}\right) \sigma=0.87$ $(\mathrm{t}, 3 \mathrm{H}, J=7.0 \mathrm{~Hz}), 1.16(\mathrm{~s}, 6 \mathrm{H}), 1.32-1.80$ $(14 \mathrm{H})$, and $3.22 \mathrm{ppm}(\mathrm{s}, 3 \mathrm{H}) ;{ }^{13} \mathrm{C} \mathrm{NMR}\left(\mathrm{CDCl}_{3}\right)$ $\sigma=14.5\left(\mathrm{CH}_{3}\right), 17.0\left(\mathrm{CH}_{2}\right), 22.5\left(\mathrm{CH}_{2}\right), 24.5$ $\left(\mathrm{CH}_{3}\right), 25.3\left(\mathrm{CH}_{2}\right), 31.5\left(\mathrm{CH}_{2}\right), 41.5\left(\mathrm{CH}_{2}\right)$, $47.3\left(\mathrm{CH}_{3}\right), 85.3(\mathrm{C})$, and $103.0 \mathrm{ppm}(\mathrm{C})$; IR (neat) 2920, 2850, 1450, 1380, 1360, 1340, 1280, $1260,1240,1180,1160,1100,1040,930,880$, and $820 \mathrm{~cm}^{-1}$; Anal. Cald for $\mathrm{C}_{13} \mathrm{H}_{26} \mathrm{O}_{3}$ : C, 67.8; H, 11.4. Found: C, 67.6; H, 11.3.

Cumene was purified by distillation after washing with concentrated sulfuric acid. Styrene was washed with $2 \%$ aqueous $\mathrm{NaOH}$ and water, and distilled under reduced pressure before use.

\section{Typical Procedure for the Thermolysis}

A $2 \mathrm{ml}$ solution of 2 in cumene was charged into a glass ampoule. The ampoule was purged with nitrogen, sealed, and immersed in a constant temperature bath. After thermolysis for a given time, the remaining perketal was determined by GLC analysis.

\section{Polymerization of Styrene}

All polymerizations were carried out in the presence of peroxide initiator in bulk in a sealed glass ampoule purged with nitrogen. Polymerization temperature was increased stepwise or continuously. Conversion of the monomer was determined by GLC and/or GPC. Number and weight average molecular weights $\left(\bar{M}_{n}\right.$ and $\bar{M}_{w}$, respectively) were determined by GPC. 


\section{REFERENCES}

1. C. S. Sheppard and V. R. Kamath, Polym. Eng. Sci., 19, 597 (1979).

2. K. Y. Choi and G. D. Lei, AIChE J., 33, 2067 (1987).

3. K. Y. Choi, W. R. Liang, and G. D. Lei, J. Appl. Polym. Sci., 35, 1547 (1988).

4. K. J. Kim and K. Y. Choi, Chem. Eng. Sci., 43, 965 (1988).

5. K. J. Kim, W. Liang, and K. Y. Choi, Ind. Eng. Chem. Res., 28, 131 (1989).

6. K. J. kim and K. Y. Choi, Chem. Eng. Sci., 44, 297 (1989).

7. W. J. Yoon and K. Y. Choi, J. Appl. Polym. Sci., 46, 1353 (1992).

8. M. A. Villalobos, A. E. Hamielec, and P. E. Wood, J. Appl. Polym. Sci., 42, 629 (1991).

9. S. Suyama, Y. Watanabe, and Y. Sawaki, Bull. Chem. Soc. Jpn., 63, 716 (1990).

10. Y. Sugihara, Y. Watanabe, H. Kumura, T. Nakamura, S. Suyama, and Y. Sawaki, Bull. Chem. Soc. Jpn., 65, 664 (1992).

11. Y. Watanabe, H. Ishigaki, H. Okada, and S. Suyama,
Bull. Chem. Soc. Jpn., 64, 1231 (1991).

12. Y. Watanabe, H. Ishigaki, and S. Suyama, Polym. J., 24, 257 (1992).

13. S. Suyama, Y. Sugihara, Y. Watanabe, and T. Nakamura, Polym. J., 24, 971 (1992).

14. R. E. Drumright, P. E. Kastl, and D. B. Priddy, Macromolecules, 26, 2246 (1993).

15. R. E. Drumright, E. Ellington, P. E. Kastl, and D. B. Priddy, Macromolecules, 26, 2253 (1993).

16. P. D. Bartlett and R. R. Hiatt, J. Am. Chem. Soc., 80, 1398 (1958).

17. K. Matsuyama and H. Kumura, J. Org. Chem., 58, 1766 (1993).

18. L. A. Singer, "Organic Peroxides," Vol. I, by D. Swern, Ed., John Wiley \& Sons, New York, 1970, p 280 and 281.

19. J. K. Kochi, "Free Radicals," Vol. II, by J. K. Kochi, Ed., John Wiley \& Sons, New York, 1973, p 684.

20. C. Walling and A. Padwa, J. Am. Chem. Soc., 85, 1593 (1963).

21. F. D. Greene, M. L. Savitz, F. D. Osterholtz, H. H. Lau, W. N. Smith, and P. M. Zanet, J. Org. Chem., 28, 55 (1963). 